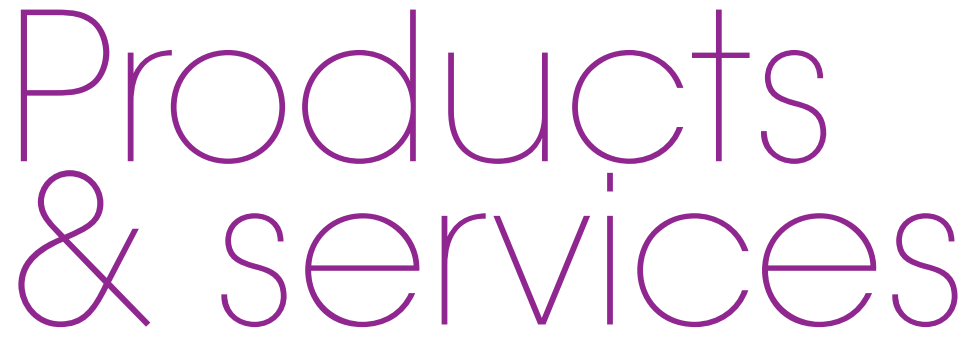

\section{THE CRUCIAL EARLY DIAGNOSIS OF TOOTH WEAR}

PRONAMEL

In 9 June 2014, GSK Consumer Healthcare, the manufacturers of Pronamel, held a meeting of dental professionals from NHS and private practice, as well as academics. The meeting discussed ground-breaking data from a recent ESCARCEL study which was sponsored by GSK. This study revealed that $29.4 \%$ of young European adults aged $18-35$ years already have moderate tooth wear

To help dental professionals in the crucial early diagnosis of tooth wear the meeting suggested the use of the Basic Erosive Wear Examination (BEWE), which facilitates consistent measurement and recording of tooth wear in practice and offers useful management guidelines.

The duration over which acid

is consumed and method of

consumption must be considered in risk

management

The BEWE is featured in the 2014 Delivering better oral health toolkit as a method for the prevention of acid wear.2 For more information on acid wear and using the BEWE to identify and manage the condition in practice, visit www.gsk-dentalprofessionals.co.uk.

Bartlett D W. Lussi A. West NX, Bouchard P. Sanz M, Bourgeois D. Prevalence of tooth wear on buccal and lingual surfaces and possible risk factors in young European adults. J Dent 2013; 41: 1007-1013. Department of Health. Delivering better ord health An evidence-based toolkit for prevention. 3rd ed 2014

\section{COLOUR CHANGING STERILISATION POUCHES}

For a sterilisation pouch that combines a variety of features, choose PeelVue+from DUX Dental.

PeelVue+ sterilisation pouches feature both an internal and external processing indicator, which change colour after the sterilisation process is complete.

In addition, the PeelVue ${ }^{+}$Closure Validators offer a visual guide printed on the pouch to aid correct sealing of the pouch

PeelVue+ sterilisation pouches are made from medicalgrade, virgin non-recycled paper and lead-free inks and are easy to close and peel open, even while wearing gloves. Once opened and the transparent film removed the paper side can function as a sterile tray liner.

With a useful colour coding to aid selection and available in 12 sizes, PeelVue+ sterilisation pouches can be used in any steam auto/Chemiclave. Their easily removable clear film also provides prompt access to instruments.

For more informationemail info@dux-dental.com or visit www. dux-dental.com.

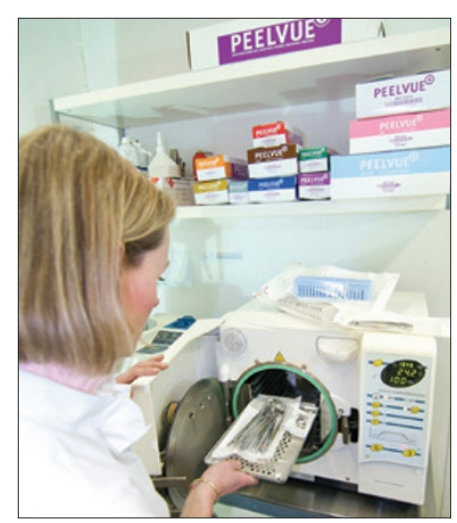

INNOVATIVE PRODUCTS AND POSTERS
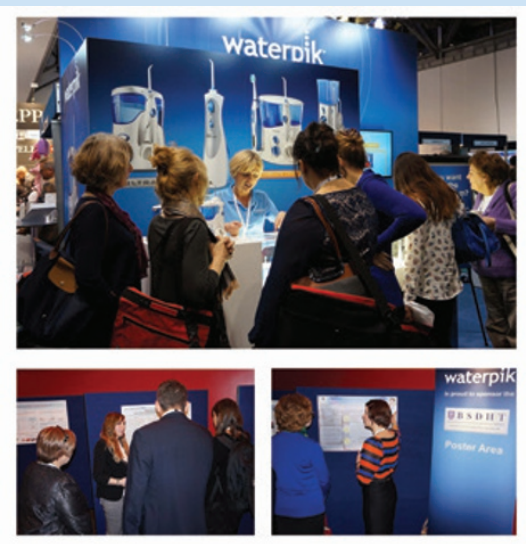

Waterpik International, Inc. delighted delegates at the 2014 British Society of Dental Hygiene and Therapy (BSDHT) Oral Health Conference \& Exhibition. Visitors were able to observe the latest products, as well as marvel at all the brilliant poster competition entries

On show was the incredibly popular Waterpik Complete Care system, combining the Waterpik Water Flosser and the Waterpik Sensonic Professional Plus Toothbrush. This outstanding system is clinically proven to be up to $159 \%$ more effective at improving gingival health than a manual toothbrush.

Delegates were equally impressed by the display of individual Waterpik Water Flossers that can remove up to $99.9 \%$ of plaque from treated areas in just three seconds. ${ }^{2}$ They have also been proven to be up to 50\% more effective than string floss for improving gingival health.

Visit www.waterpik.co.uk for more information. Waterpik products are available in Boots and Superdrug.

Goyal C R, Lyle D M, Qagish J G, Schuller R. The addition of water flosser to power tooth brushing: effect on bleeding, gingivitis, and plaque. Ing: effect on bleeding, gi.

Gorur A, Lyle D M, Schaudinn C, Costerton J W. Biofilm removal with a dental water jet. Com1): $7-16$

If you would like to promote your products or services direct to the dental industry in BDJ Team, call Andy May on 02078434785 or emaila.may@nature.com 